\title{
Tullock on the Football Pitch
}

\author{
Stephen Dobson ${ }^{1}$, John Goddard ${ }^{2} \&$ Frank Stähler ${ }^{3}$ \\ ${ }^{1}$ Hull University Business School, University of Hull, UK \\ ${ }^{2}$ Bangor Business School, Bangor University, UK \\ ${ }^{3}$ School of Business and Economics, University of Tuebingen, Germany \\ Correspondence: Stephen Dobson, Hull University Business School, University of Hull, HU6 7RX, UK
}

Received: September 26, 2014

Accepted: October 15, 2014

Available online: Ocotber21, 2014

doi:10.11114/aef.v1i2.564

URL: http://dx.doi.org/10.11114/aef.v1i2.564

\begin{abstract}
A simple Tullock contest model is used to predict levels of effort in English professional football (soccer). The effort of the teams is reflected in the numbers of fouls committed and the numbers of yellow and red cards awarded. Effort levels are found to be higher in matches between evenly talented teams, confirming the idea that asymmetries result in lower effort by participants. The results also suggest that teams' effort levels are strategic complements.
\end{abstract}

Keywords: Tullock contest, English football, asymmetries, strategic complements

\section{Introduction}

Tullock's (1980) contest model is a standard tool in economics and is well known in the literature on tournaments, contests, and rent-seeking games. Corchon (2007) reviews this literature. In a winner-take-all contest, the model defines the ex ante probability of winning as a ratio of each contestant's investment relative to the sum of investments supplied by all contestants. In general, however, the Tullock model does not predict whether effort is a strategic substitute or complement in the sense of Bulow, Geanakoplos and Klemperer (1985); this depends upon the payoff structure.

Empirical applications of the Tullock model are rare, due in part to the non- observability of effort. For example, data on bribes and the transfer of intangible assets in rent-seeking contests may be unobtainable. This paper contributes to the non-experimental empirical Tullock contest literature (Note 1). The behavior of teams in English professional football (soccer) is modeled as a Tullock contest. One important influence on the outcome of football matches (apart from underlying team quality) is the contributed effort of the teams. Working hard to press the opposition and make tackles will eventually result in foul play and yellow and red cards being awarded. Therefore, effort is measured by the numbers of fouls committed by the home and away teams, and the numbers of yellow and red cards awarded against each team (Note 2).

The remainder of this paper is organized as follows. Section 2 develops the theoretical model. Section 3 describes the data and the empirical model. Section 4 reports the empirical results; and Section 5 concludes.

\section{Theoretical Framework}

This section develops a simple contest model for football match outcomes. Before the match, each manager (coach) decides independently on the conduct of his team: specifically, whether the team will work hard to tackle players of the opposition. Effort is measured by a continuous variable $e_{i}>0$, where $i=1,2$ denotes the home and away teams. Greater effort carries a cost, because it increases the probability that a player receives a caution (yellow card) or is dismissed from the field of play for the remainder of the game (red card). A red card leads to a suspension, preventing the player from appearing in either one, two or three of his team's next scheduled games. A player who accumulates five (ten) yellow cards in different games within the season before 31 December (10 April) receives a one (two) match suspension. The marginal cost of effort, denoted $c_{i}$, may differ between teams. The marginal cost of effort is higher the larger is the number of injured and suspended players in team $i$ 's playing squad, and the smaller is the overall size of the squad (Note 3).

Both teams' effort levels influence the probabilities for the match outcome. For simplicity, the theoretical model is developed by incorporating the following weighted sum of the home team's win probability and the draw probability 
into the teams' expected payoff functions: $p\left(e_{1}, e_{2}\right)=\operatorname{prob}\left(\right.$ home win) $+0.5 \operatorname{prob}(\mathrm{draw}) . p\left(e_{1}, e_{2}\right)$ is the home team's success probability, and $1-p\left(e_{1}, e_{2}\right)$ is the away team's success probability (Note 4 ).

The teams are assumed to be heterogeneous in underlying quality, and an asymmetric contest model is required (Corchon, 2000). The absolute quality if team $i$, which is common knowledge before the match, is denoted $\beta_{i}$. Home-field advantage, arising from the support the home team receives from the crowd and from any possible refereeing bias (Dawson, Dobson, Goddard \& Wilson, 2007), is represented by a parameter $h$. The home team's prior success probability, defined for $e_{1}=e_{2}=0$, is

$$
r=p(0,0)=\frac{\beta_{1}+h}{\beta_{1}+\beta_{2}+h}
$$

Positive effort levels by either team influence the actual success probabilities, such that

$$
p\left(e_{1}, e_{2}\right)=\frac{e_{1} r}{e_{1} r+e_{2}(1-r)}
$$

We assume that $p\left(e_{1}, e_{2}\right)$ is increasing in $e_{1}$ and decreasing in $e_{2}$ over the range of realistic values for $e_{1}$ and $e_{2}$ that any team would select. For extreme values of $e_{1}$ (for example) beyond this range, $p\left(e_{1}, e_{2}\right)$ might be decreasing in $e_{1}$, because extreme effort raises team $i$ 's probability of having players dismissed to a level that reduces team $i$ 's probability of success in the current match. It is obvious, however, that teams seeking to maximize their own success probabilities would not select such extreme values of $e_{1}$ or $e_{2}$. Accordingly, the possible negative relationship between the levels of effort and the success probability at extreme values of $e_{1}$ or $e_{2}$ is not represented by (2).

The expected payoffs for teams 1 and 2 are

$$
\pi_{1}=p U_{1}-c_{1} e_{1}, \quad \pi_{2}=(1-p) U_{2}-c_{2} e_{2}
$$

where $U_{i}$ represents the gross payoff (before deducting the cost arising from greater effort) to team $i$ from winning the match (Note 5). $U_{i}$ depends on the importance of the match to team $i$. For example, $U_{i}$ is large if team $i$ is near the top of its divisional league table and in contention for the championship, qualification for European competition, or promotion to a higher division. $U_{i}$ is also large if team $i$ is near the bottom of its divisional table and in danger of relegation to the division below. $U_{i}$ is small when team $i$ is out of contention for any of these end-of-season outcomes.

The absolute team quality measures $\beta_{1}$ and $\beta_{2}$ are determined by the quality of playing talents, the ability of the managers, and the teams' tactical capabilities. All of these determinants may vary over time, even within a football season. Prior to each match, the team managers select $e_{1}$ and $e_{2}$ so as to maximize their teams' expected payoffs. The non-cooperative solution for the equilibrium levels of effort is

$$
e_{1}^{*}=\frac{(1-r) r c_{2} U_{1}^{2} U_{2}}{\left(r c_{2} U_{1}+(1-r) c_{1} U_{2}\right)^{2}} \quad e_{2}^{*}=\frac{(1-r) r c_{1} U_{1} U_{2}^{2}}{\left(r c_{2} U_{1}+(1-r) c_{1} U_{2}\right)^{2}}
$$

From contest theory it is well known that the response of the strategic variable (the level of effort) to a small change in the payoffs and the individual costs depends upon the levels of the payoffs and costs. The partial derivatives of (4) with respect to the home team win payoff $U_{l}$ and with respect to the marginal cost of effort $c_{l}$ are

$$
\begin{aligned}
& \frac{\partial_{1}^{*}}{\partial U_{1}}=\frac{2(1-r)^{2} r c_{1} c_{2} U_{1} U_{2}^{2}}{\left(r c_{2} U_{1}+(1-r) c_{1} U_{2}\right)^{3}}>0, \\
& \frac{\partial_{1}^{*}}{\partial_{1}}=\frac{U_{1}}{c_{1}} \frac{\partial_{1}^{*}}{\partial U_{1}}<0, \\
& \frac{\partial_{2}^{*}}{\partial U_{1}}=\frac{(1-r) r c_{1} U_{1} U_{2}^{2}\left(r c_{2} U_{1}-(1-r) c_{1} U_{2}\right)}{\left(r c_{2} U_{1}+(1-r) c_{1} U_{2}\right)^{3}}, \\
& \frac{\partial_{2}^{*}}{\partial c_{1}}=\frac{U_{1}}{c_{1}} \frac{\partial_{2}^{*}}{\partial U_{1}}
\end{aligned}
$$

Equivalent results can be derived for small changes in the away team's win payoff. In (5), $\partial_{1}^{*} / \partial U_{1}\left(\partial e_{1}^{*} / \partial c_{1}\right)$ is unambiguously positive (negative). This leads to

Result 1: An increase in the payoff from a win for either team will unambiguously increase that team's level of effort. An increase in the own cost of effort will unambiguously decrease that team's level of effort.

The effect on effort of an increase in the opposing team's payoff from a win is ambiguous, and the effect of an increase in the opposing team's marginal cost of effort is also ambiguous. We focus on an increase in $U_{l}$, which leads to the same qualitative results as a decrease in $c_{1}$. In (5), $\alpha_{2}^{*} / \partial U_{1}$ is positive (negative) if 


$$
\frac{(1-r) U_{2}}{r U_{1}}>(<) \frac{c_{2}}{c_{1}} .
$$

$r U_{1}$ and $(1-r) U_{2}$ are the two teams' expected prior payoffs. The away team will increase (decrease) its level of effort if its relative expected prior payoff - compared to the home team - is larger (smaller) than its relative marginal cost of effort. In this case, there is more (less) at stake for the away team, taking into account the relative costs of effort. As a result, the away team responds with a higher (lower) level of effort to an increase in the home team's gross payoff.

By substituting (4) into (2), the equilibrium solution for the home team's success probability is

$$
p=\frac{\beta_{1}+h}{\beta_{1}+\beta_{2} \frac{c_{1} U_{2}}{c_{2} U_{1}}+h}
$$

Comparing (6) with (1), the home team's equilibrium success probability is larger (smaller) than its prior success probability (i) if the home team's win payoff is larger (smaller) than the away team's win payoff, and effort costs are identical, and (ii) if the home team's marginal costs of effort are smaller (larger) than the away team's marginal costs of effort and payoffs are identical. Equation (6) shows that $\mathrm{c}_{\mathrm{i}}$ and $\mathrm{U}_{\mathrm{i}}$ play similar roles in the model. Finally, the values of $r$ at which the teams' levels of effort are maximized are derived from (4) for $c_{1}=c_{2}$. The maximum value of $e_{1}$ is obtained when $r=U_{2} /\left(U_{1}+U_{2}\right)$, and the maximum value of $e_{2}$ is obtained when $r=U_{1} /\left(U_{1}+U_{2}\right)$. This leads to

Result 2: Assuming identical marginal costs of effort, if the teams' payoffs from a win are the same, the teams'levels of effort are maximized when the game is evenly balanced after allowing for home-field advantage, in the sense that each team has a prior success probability of 0.5. If the teams' payoffs from a win are unequal, the teams'levels of effort are maximized when the prior success probability of the team with the larger (smaller) payoff is below (above) 0.5 .

\section{Data and Empirical Model}

The data for the empirical analysis comprises all 12216 games played in the English Premier League (the Premiership) and the three divisions of the English Football League (currently known as the Championship, League One and League Two) during the six football seasons from 2001/02 to 2006/07 (inclusive). The data source is www.football-data.co.uk. The dependent variables in the empirical models are the numbers of fouls committed by each team per game, and the numbers of yellow and red cards awarded against each team per game.

Table 1 reports descriptive statistics for the fouls, yellow and red cards data. The sample means for the numbers of fouls awarded against the home and away teams are 12.4 and 13.1 per game, respectively. Although the number of fouls per game takes the form of count data, the number of cells appears sufficiently large to justify treating these data as continuous. Accordingly, the fouls equations are estimated as Seemingly Unrelated Regressions (SUR). The interdependence between the fouls committed by the home and away teams is captured by the contemporaneous correlation between the disturbances of the home and away team equations.

\begin{tabular}{|c|c|c|c|c|c|c|c|c|}
\hline \multirow{2}{*}{$\begin{array}{l}\text { Number } \\
\text { of fouls, } \\
\text { F }\end{array}$} & \multicolumn{2}{|c|}{$\begin{array}{l}\text { Number of games in } \\
\text { which F fouls were } \\
\text { awarded against: }\end{array}$} & \multirow{2}{*}{$\begin{array}{l}\text { Number } \\
\text { of yellow } \\
\text { cards, Y }\end{array}$} & \multicolumn{2}{|c|}{$\begin{array}{l}\text { Number of games in } \\
\text { which Y yellow cards } \\
\text { were awarded against: }\end{array}$} & \multirow{2}{*}{$\begin{array}{l}\text { Number } \\
\text { of red } \\
\text { cards, } \mathrm{R}\end{array}$} & \multicolumn{2}{|c|}{$\begin{array}{l}\text { Number of games in } \\
\text { which } \mathrm{R} \text { red cards } \\
\text { were awarded against: }\end{array}$} \\
\hline & $\begin{array}{l}\text { Home } \\
\text { team }\end{array}$ & $\begin{array}{l}\text { Away } \\
\text { team }\end{array}$ & & $\begin{array}{l}\text { Home } \\
\text { team }\end{array}$ & $\begin{array}{l}\text { Away } \\
\text { team }\end{array}$ & & $\begin{array}{l}\text { Home } \\
\text { team }\end{array}$ & $\begin{array}{l}\text { Away } \\
\text { team }\end{array}$ \\
\hline $0-4$ & 167 & 143 & 0 & 3535 & 2294 & 0 & 11353 & 10856 \\
\hline $5-9$ & 2762 & 2203 & 1 & 4172 & 3644 & 1 & 817 & 1263 \\
\hline $10-14$ & 5818 & 5561 & 2 & 2829 & 3287 & 2 & 43 & 92 \\
\hline $15-19$ & 2924 & 3464 & 3 & 1184 & 1905 & 3 & 3 & 4 \\
\hline $20-24$ & 503 & 778 & 4 & 389 & 754 & 4 & 0 & 1 \\
\hline $25+$ & 42 & 67 & $5+$ & 107 & 332 & & & \\
\hline Total & 12216 & 12216 & Total & 12216 & 12216 & Total & 12216 & 12216 \\
\hline Mean & 12.4007 & 13.1212 & 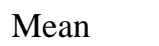 & 1.2687 & 1.6957 & Mean & 0.0747 & 0.1198 \\
\hline St. dev & 3.9759 & 4.1345 & Variance & 1.2834 & 1.6706 & Variance & 0.0776 & 0.1234 \\
\hline
\end{tabular}

Table 1. Descriptive Statistics: Fouls, Yellow Cards and Red Cards

The sample means for the numbers of cards awarded against the home and away teams per game are 1.2687 and 1.6957 (yellow) and 0.0747 and 0.1198 (red), respectively. In this case the numbers of cells are small, necessitating the use of count data regression models. As Table 1 shows, the sample variances are similar to the sample means, which suggests that the Poisson distribution is a suitable probability model. The yellow and red cards equations are estimated using a bivariate distribution obtained from the convolution of two univariate zero-inflated Poisson probability functions via the Frank copula (Lee, 1999) (Note 6). The copula function contains a parameter that controls for interdependence between 
the cards awarded against the home and away teams. The bivariate cards regressions reported in Section 4 express the $\log$-mean number of cards for each team as a linear function of covariates that are defined below.

According to the theoretical analysis developed in Section 2, the teams' strategic choices for their levels of effort depend upon two factors: (i) differences between the payoffs from a win for each team; and (ii) the degree of balance or imbalance between the teams' prior success probabilities. Controls are included for (i) and (ii), and for one further non-strategic determinant of the levels of foul play: (iii) weaker teams that tend to spend more of the game defending are expected to commit more fouls and collect more cards than stronger teams that spend more time attacking.

In controlling for (i) above, it is assumed that the two teams' payoffs from a win may differ once a stage of the season has been reached at which some teams have dropped out of contention for championship, European qualification, promotion or relegation outcomes. The 0-1 dummy variable HSIG $=1$ if the game is significant for end-of-season outcomes for the home team, and ASIG = 1 if the game is significant for the away team. The algorithm that determines whether the game is significant assesses whether it is arithmetically possible (before the game is played) for the team to win the championship, qualify for European competition, be promoted or be relegated, if all other teams currently in contention for the same outcome take one league point on average from each of their remaining games (Note 7).

In order to control for (ii) and (iii) above, relative team quality is measured using HPROB=prob(home win) $+0.5 \times$ prob(draw). HPROB corresponds to the variable $r$, the home team's prior success probability, in the theoretical model. A numerical value for HPROB for each of the $\mathrm{N}=12216$ sample games is generated from the results forecasting model described in full by Goddard (2005) (Note 8). Included among the covariates of this model are HSIG and ASIG (as defined above), which control for the effect of incentives on the result probabilities. In the present case, HPROB should reflect prior success probabilities, which depend upon the underlying quality of the two teams, but should not incorporate any incentives effects. Therefore in generating HPROB from the forecasting model, we reset the values of HSIG and ASIG to zero for the (out-of-sample) games for which the forecasts are produced.

A convenient measure of the competitiveness of the game, or uncertainty of game outcome, is UNCERT $=\mathrm{HPROB} \times(1-$ HPROB). UNCERT is maximized when HPROB $=0.5$. A positive relationship is expected between UNCERT and the numbers of fouls and cards awarded. Table 2 reports summary statistics for the HPROB, UNCERT, HSIG and ASIG covariates.

Table 2. Descriptive Statistics: Hprob, Uncert, Hsig and Asig

\begin{tabular}{lccccc}
\hline & Mean & $\begin{array}{c}\text { Standard } \\
\text { deviation }\end{array}$ & 1st quartile & 2nd quartile & 3rd quartile \\
\hline HPROB & 0.5922 & 0.0938 & 0.5312 & 0.5955 & 0.6555 \\
UNCERT & 0.2327 & 0.0203 & 0.2251 & 0.2398 & 0.2475 \\
HSIG & 0.9501 & - & - & - & - \\
ASIG & 0.9510 & - & - & - & - \\
\hline
\end{tabular}

Finally, the estimations include controls for several other factors that might be expected to influence the number of fouls committed and cards awarded. Individual football season dummy variables control for changes over time in the content and interpretation of the rules relating to foul play; referee fixed effects control for variation among referees in the propensity to award fouls and cards; and individual team fixed effects control for other unobservable differences between teams (Note 9).

\section{Empirical Results}

The estimation results are reported in Table 3. Column (1) reports the SUR estimations for the numbers of fouls committed by the home and away teams, and columns (2) and (3) report maximum likelihood estimation results for the bivariate regressions for the numbers of cards awarded against the home and away teams.

Table 3. Estimation Results

\begin{tabular}{lllllll}
\hline & \multicolumn{3}{c}{ Home team } & \multicolumn{3}{c}{ Away team } \\
\hline \multirow{2}{*}{ HSIG } & Fouls & $\begin{array}{l}\text { Yellow } \\
\text { cards }\end{array}$ & $\begin{array}{l}\text { Red } \\
\text { Cards }\end{array}$ & Fouls & $\begin{array}{l}\text { Yellow } \\
\text { cards }\end{array}$ & $\begin{array}{l}\text { Red } \\
\text { cards }\end{array}$ \\
& 0.028 & -0.004 & -0.087 & $0.244^{*}$ & $0.112^{* *}$ & $0.201^{*}$ \\
ASIG & $(0.17)$ & $(-0.07)$ & $(-0.53)$ & $(1.41)$ & $(2.04)^{* * * *}$ & $(1.35)^{* *}$ \\
& $0.353^{* *}$ & $0.119^{* * *}$ & $0.569^{* * *}$ & $0.299^{* *}$ & $0.241^{* * *}$ & $0.349^{* *}$ \\
& $(2.14)$ & $(2.52)$ & $(2.62)$ & $(1.70)$ & $(4.41)$ & $(2.21)$ \\
\hline \multirow{2}{*}{ HPROB } & $-1.340^{* *}$ & $-0.889^{* * *}$ & -0.190 & $1.918^{* * *}$ & $0.606^{* * *}$ & $0.775^{*}$ \\
& $(-2.22)$ & $(-4.71)$ & $(-0.31)$ & $(2.91)$ & $(2.89)$ & $(1.47)^{* * *}$ \\
UNCERT & $8.060^{* * *}$ & 0.593 & $6.643^{* *}$ & $12.637^{* * *}$ & $1.941^{* *}$ & $4.916^{* *}$ \\
& $(2.84)$ & $(0.69)$ & $(2.11)$ & $(4.32)$ & $(2.05)$ & $(2.05)$ \\
\hline
\end{tabular}


Notes: the fouls equations are estimated as Seemingly Unrelated Regressions (SUR). The yellow and red cards equations are estimated as a bivariate Poisson regression. Ancillary parameters (allowing for interdependence between the home team and away team fouls or cards, and the zero-inflation parameter) are not reported. Additional controls included in these regressions are individual effects for (i) football seasons, (ii) teams and (iii) referees. Coefficients are not reported. $* * *, * * *$ denote coefficients significant at the $10 \%, 5 \%$ and $1 \%$ levels, respectively, one-tail tests. z-statistics are reported in parentheses.

The coefficients on HSIG in the equations for home-team fouls and cards are insignificant, while the coefficients on ASIG are positively signed and significant at the $10 \%$ level or lower, using one-tail tests. The coefficients on HSIG and ASIG in the equations for away-team fouls and cards are positively signed and significant at the 5\% level or lower.

These results provide some support for Result 1 (see Section 2), and suggest that football teams' strategies are influenced by the magnitudes of their own payoffs. However, the tendency to exert more effort if end-of-season championship, European qualification, promotion or relegation outcomes are at stake, and exert less effort if nothing is at stake, appears more pronounced for away teams than for home teams. A possible interpretation is that away teams tend to 'ease off' in unimportant end-of-season games; while home teams, perhaps more highly conscious of the critical scrutiny of their own supporters, feel obliged to demonstrate maximum commitment at all times. According to the theoretical model developed in Section 2, the relationship between the opposing team's payoff and each team's own strategy is ambiguous. Empirically, however, the results reported in Table 3 suggest that teams tend to exert more effort if the opposing team has end-of-season championship, European qualification, promotion or relegation outcomes at stake, and exert less effort if nothing is at stake.

The coefficients on UNCERT are positively signed (as expected) in every case. Two of the three coefficients on UNCERT for the home team (in the fouls and the red cards equations) are significant at the $5 \%$ level or below, and all three coefficients on UNCERT for the away team are significant at the 5\% level or lower. These findings are consistent with Result 2 (see Section 2). Football teams tend to exert more effort in games involving teams that are evenly balanced, and exert less effort if there is a large disparity between the quality of the two teams.

Finally, the coefficients on HPROB are negatively signed in the equations for the home team, and positively signed in the equations for the away team. Two of the three coefficients on HPROB for the home team are significant at the 5\% level or lower, and all three coefficients on HPROB for the away team are significant at the $10 \%$ level or lower. These results indicate that weaker teams (as measured by the prior success probability) tend to commit more fouls and collect more cards than stronger teams.

\section{Conclusion}

Tullock's contest success function has been widely used in the contest theory literature. Although the Tullock model provides a number of testable predictions about the behavior of agents in winner-take-all contests, empirical applications have been few and far between due to constraints on the availability of suitable data. This paper makes progress on testing the implications of the Tullock contest model using data from English professional football. In the empirical model the effort of the teams is reflected in the numbers of fouls committed and the numbers of yellow and red cards awarded. Effort tends to be higher in matches between evenly balanced teams, thus confirming a well known result that asymmetries will reduce contributions by participants (teams). It is also found that teams' behavior (especially those playing away) alters in matches that matter: levels of effort are higher when end-of-season championship, European qualification, promotion or relegation outcomes are at stake. The empirical results also suggest that the teams' levels of effort are strategic complements.

\section{References}

Bulow, J., Geanakoplos, J., \& Klemperer, P. (1985). Multimarket oligopoly: strategic substitutes and complements. Journal of Political Economy, 93, 488-511.

Caliendo, M., \& Radic, D. (2006). Ten do it better, do they? An empirical analysis of an old football myth. IZA Discussion Paper, 2158.

Corchon, L.C. (2000). On the allocative effects of rent seeking. Journal of Public Economic Theory, 4, 483-491. http://dx.doi.org/10.1111/1097-3923.00047

Corchon, L. C. (2007). The theory of contests: a survey. Review of Economic Design, 11, 69-100. http://dx.doi.org/10.1007/s10058-007-0032-5

Dawson, P., Dobson, S., Goddard, J., \& Wilson, J. (2007). Are football referees really biased and inconsistent? Evidence from the English Premier League. Journal of the Royal Statistical Society, Series A, 170, 231-250. http://dx.doi.org/10.1111/j.1467-985X.2006.00451.X

Goddard, J. (2005). Regression models for forecasting goals and results in professional football. International Journal 
of Forecasting, 21, 331-340. http://dx.doi.org/10.1016/j.ijforecast.2004.08.002

Harbring, C., \& Irlenbusch, B. (2003). An experimental study on tournament design. Labour Economics, 10, 443-464. http://dx.doi.org/10.1016/S0927-5371(03) 00034-4

Harbring, C., Irlenbusch, B., Krakel, M., \& Selten, R. (2007). Sabotage in corporate contests - an experimental analysis. International Journal of the Economics of Business, 14, 367-392. http://dx.doi.org/10.1080/13571510701597445

Lee, A. (1999). Modelling rugby league data via bivariate negative binomial regression. Australian and New Zealand Journal of Statistics, 41, 153-171. http://dx.doi.org/10.1111/1467-842X.00070

Müller, W., \& Schotter, A. (2007). Workaholics and drop outs in optimal organizations. Working Paper, Centre for Experimental Social Science, New York University.

Sheremeta, R. (2009). Contest design: an experimental investigation. Economics Working Paper 1231, Department of Economics, Purdue University.

Tullock, G. (1980). Efficient rent seeking. In J.M. Buchanan, R. Tullock, \& G. Tullock (Eds.), Toward a Theory of Rent Seeking Society, 97-112, Texas A\&M University Press, College Station.

\section{Notes}

${ }^{1}$ There is a large literature that tests the implications of the contest model (or variants of it) using experimental data (e.g., Harbring \& Irlenbusch, 2003; Harbring, Irlenbusch, Krakel \& Selton, 2007; Müller \& Schotter, 2007; Sheremeta, 2009). While this literature is clearly useful, it is not obvious that behaviour under stylized laboratory conditions generalises to real world situations.

${ }^{2}$ Teams that make more (less) effort to tackle the opposition can expect to commit more (fewer) fouls and collect more (fewer) yellow and red cards than teams that make less (more) effort. A foul in football is an unfair act by a player against an opponent which is deemed by the referee to contravene Law 12 of the Laws of the Game. If the referee judges the foul play to be serious he may decide that it warrants a disciplinary sanction (yellow or red card) in accordance with Law 12. A yellow card is awarded for less serious transgressions. There is no further punishment within the game, unless the player commits a second similar offence, in which case a red card is awarded and the player is expelled for the rest of the game (with no replacement permitted). A red card, also known as a sending-off or dismissal, is awarded for more serious offences and results in immediate expulsion (again, with no replacement permitted).

${ }^{3}$ The costs of effort may change within a game, for example if one player has been sent off and a further red card would weaken the team disproportionately. Caliendo and Radic (2006) show that the timing of such events can be important for game outcomes. Consideration of changes during a game would produce similar theoretical results to those across games.

${ }^{4}$ This formulation ensures that the two teams' success probabilities sum to one, and by so doing simplifies the algebra without any loss of generality. The weight attached to prob(home win) in the definition of $p\left(e_{1}, e_{2}\right)$ is twice the weight attached to prob(draw). Therefore by assuming (below) that the teams' expected gross utility payoffs from the game are obtained by multiplying the utility value of a win by $p\left(e_{1}, e_{2}\right)$, it is assumed implicitly that the utility value of the draw is half the utility value of the win. In accordance with expected utility theory, under the league points system of three points for a win and one point for a draw, this set-up implies risk aversion on the part of team managers. Other weightings for the utility values of the win and the draw can be accommodated by the model without affecting fundamentally any of the results that are derived below, but at the cost of introducing some additional algebraic complexity.

${ }^{5}$ Payoffs are normalized such that a loss implies a zero gross payoff.

${ }^{6}$ The marginal probability function for $z_{i}=$ number of yellow or red cards awarded against the home team $(i=1)$ and away team $(i=2)$ is denoted $\mathrm{f}_{\mathrm{i}}\left(z_{i}\right)=\exp \left(-\lambda_{i}\right) \lambda_{i}^{z_{i}} / z_{i}$ ! for $z_{i}=0,1,2, \ldots$ The joint distribution function is constructed by substituting the two univariate distribution functions, $F_{i}\left(z_{i}\right)$, into the Frank copula. The bivariate joint distribution function is:

$$
G\left[F_{1}\left(z_{1}\right), F_{2}\left(z_{2}\right)\right]=\frac{1}{\varphi} \ln \left(1+\frac{\left\{\exp \left[\varphi F_{1}\left(z_{1}\right)\right]-1\right\}\left\{\exp \left[\varphi F_{2}\left(z_{2}\right)\right]-1\right\}}{\exp (\varphi)-1}\right), \text { where } \varphi \neq 0 \text { is an ancillary parameter. }
$$

The zero-inflated joint probabilities are: $(1-\theta) P\left(z_{1}, z_{2}\right)+\theta D\left(z_{1}, z_{2}\right)$, where $P\left(z_{1}, z_{2}\right)$ is the bivariate joint probability function corresponding to $G\left[F_{1}\left(z_{1}\right), F_{2}\left(z_{2}\right)\right], D(0,0)=1$ and $D\left(z_{1}, z_{2}\right)=0$ for $\left(z_{1}, z_{2}\right) \neq(0,0)$, and $\theta$ is an ancillary parameter. The 
zero-inflated adjustment allows the probabilities for the cell $\left(\mathrm{z}_{1}=0, \mathrm{z}_{2}=0\right)$ to be larger than is suggested by the Poisson distribution: an empirical regularity that is evident in the current data.

${ }^{7}$ Alternative algorithms, based on different assumptions concerning the average performance of competing teams over their remaining games, alter the classification of a small proportion of games at the margins, but the implications for the estimation results are negligible.

${ }^{8}$ This model generates probabilities for home win, draw and away win outcomes, based solely on historical data that are available prior to the game in question. Full details are reported in Goddard (2005), and are not repeated here.

${ }^{9}$ The season dummies are $S_{s}=1$ if the game is played in season s; 0 otherwise (s represents seasons 2002/03 to 2006/07 inclusive; 2001/02 is the reference category). The referee fixed effects are $R_{r}=1$ if the game is officiated by referee $r$; 0 otherwise ( $r=1 \ldots 106$ represents referees who officiated at least 30 games within the observation period; those referees who officiated fewer than 30 games each form the reference category). The team fixed effects are constant over all home games or away games for each team.

\section{(c) $)$ EY}

This work is licensed under a Creative Commons Attribution 3.0 License. 